Article

\title{
Sustainable Production of Stiff and Crystalline Bacterial Cellulose from Orange Peel Extract
}

\author{
Sanosh Kunjalukkal Padmanabhan ${ }^{1}$, Francesca Lionetto ${ }^{1} *{ }^{\mathbb{C}}$, Rossella $\mathrm{Nisi}^{2}{ }^{2}$, Mariangela Stoppa ${ }^{2}$ \\ and Antonio Licciulli ${ }^{1}$ \\ 1 Department of Engineering for Innovation, University of Salento, Via Arnesano, 73100 Lecce, Italy; \\ sanosh.padmanabhan@unisalento.it (S.K.P.); antonio.licciulli@unisalento.it (A.L.) \\ 2 Biofaber Srl, Via Luigi di Savoia, 19, 72023 Mesagne, Italy; nisirossella@gmail.com (R.N.); \\ mariangelastoppa@gmail.com (M.S.) \\ * Correspondence: francesca.lionetto@unisalento.it
}

check for

updates

Citation: Padmanabhan, S.K.;

Lionetto, F.; Nisi, R.; Stoppa, M.; Licciulli, A. Sustainable Production of Stiff and Crystalline Bacterial Cellulose from Orange Peel Extract. Sustainability 2022, 14, 2247. https:// doi.org/10.3390/su14042247

Academic Editors: Tomas Baležentis, Grigorios L. Kyriakopoulos and Dalia Streimikiene

Received: 31 December 2021 Accepted: 15 February 2022 Published: 16 February 2022

Publisher's Note: MDPI stays neutral with regard to jurisdictional claims in published maps and institutional affiliations.

Copyright: () 2022 by the authors Licensee MDPI, Basel, Switzerland. This article is an open access article distributed under the terms and conditions of the Creative Commons Attribution (CC BY) license (https:// creativecommons.org/licenses/by/ $4.0 /)$.

\begin{abstract}
In this work, a potentially economic and environmentally friendly method for the synthesis of bacterial cellulose (BC) by Gluconacetobacter xylinus from a biomass containing orange peel extract was evaluated. Orange peel extract was used as a culture medium without any hydrolysis treatment, thus speeding up the synthesis procedure. The efficacy of orange peel as a carbon source was compared with that of sucrose. The orange peel extract formed thicker cellulose gels than those formed using sucrose. X-ray diffraction (XRD) revealed both a high crystallinity index and crystallite size of BC nanofibers in samples obtained from orange peel (BC_Orange). Field emission scanning electron microscopy (FE-SEM) revealed a highly densely packed nanofibrous structure (50 $\mathrm{nm}$ in diameter). BC_Orange presented a two-fold increase in water holding capacity (WHC), and dynamic mechanical analysis (DMA) showed a $44 \%$ increase in storage modulus compared to sucrose derived BC. These results showed that the naturally available carbon sources derived from orange peel extract can be effectively used for BC production. The orange-based culture medium can be considered a profitable alternative to the generation of high-value products in a virtuous circular economy model.
\end{abstract}

Keywords: bacterial cellulose; biopolymer; agro-industrial waste; biomass; viscoelastic properties; biomaterials; bioprocess; orange peel waste

\section{Introduction}

Cellulose is a widely used biopolymer obtained using different methods such as extraction, biosynthesis, enzymatic synthesis and chemosynthesis. Plants and microorganisms are the two main sources in cellulose production [1]. Cellulose extraction from plants, such as sugar palm, water hyacinth, and lemongrass, is the most used method [2,3]. Cellulose is also produced by biosynthesis in some types of bacteria (Alcaligenes, Salmonella, Gluconacetobacter xylinus etc.) [4,5], algae (Gelidium elegans, Posidonia oceanica) [6] and fungi (Aspergillus ornatus, Penicillium, etc.) [7]. Gram-negative bacterium Gluconacetobacter xylinus is one of the commercially important bacteria strains used for cellulose biosynthesis [8]. Cellulose derived from bacteria by the fermentation of sugar is generally known as bacterial cellulose (BC). The bacterium Acetobacter xylinum can produce high-aspect-ratio nanofibers with a three-dimensional (3D) porous network, as it is secreted in the form of ribbon-shaped fibrils which are less than $100 \mathrm{~nm}[9]$.

There is increasing demand for bacterial cellulose hydrogels, because of their unique 3D web-like nanofibrous network structure with good mechanical properties, especially flexibility, hydrophilicity ( $99 \%$ water), non-toxicity and biocompatibility. These advantages make them extensively used in different fields from food to the cosmetic industry, the paper industry [10-12], and in various biomedical applications such as drug delivery, tissue engineering and wound dressing [13-16]. However, to produce $B C$, bacteria require glucose or an organic substrate to turn into cellulose polymers. Hestrin-Schramm (HS) medium 
is the most commonly used medium for the production of $\mathrm{BC}$ by bacteria, consisting of a fixed concentration of glucose, yeast and peptone [17]. However, due to the high cost of the HS medium, researchers are investigating more economic strategies, i.e., to use cheaper nutrients, such as by-products of the agri-food industry for the commercial production of BC [18].

Waste and by-products from food, agriculture and brewery industries are most commonly investigated for microbial cultivation because they are rich sources of carbon. Fruit wastes, i.e., oranges, grapefruits and bananas, are used as natural carbon sources $[18,19]$. Currently, citrus waste is used for the production of different value-added products such as citric acid, bioethanol, biosurfactants and cellulose [20,21].

Citrus waste and residues, especially from orange fruits, are used as feedstock for BC production because of their wide availability [22]. Orange peels are a rich source of soluble sugars and insoluble polysaccharides [23]. Orange peel consists of sugars (30-40\%), pectin (15-25\%), cellulose (8-10\%) and hemicellulose (5-7\%) [24]. The soluble sugars can be directly utilized by Gluconacetobacter xylinus as a carbon source for BC production. This means that orange peel has great potential to be used as a feedstock in BC production. Furthermore, the process is considered to be eco-friendly, promoting a circular economy. Studies found that, when orange peel waste was used as a carbon source, BC production showed up to six times higher yields than a conventional medium (Hestrin and Schramm) [25]. In many studies, enzymatic hydrolysis, as well as chemical hydrolysis, was performed to convert the carbohydrates present in the orange peels into fermentable sugars $[22,25]$. However, these processes are time-consuming and require chemicals and purification steps.

In this study, a biosynthesis process of bacterial cellulose using aqueous extracts from orange peel was evaluated. The novelty of the proposed method is in the absence of a hydrolysis step during the extraction process. The BC produced from orange peels was fully characterized by X-ray diffraction (XRD), Fourier transform infrared spectra (FTIR), and field-emission scanning electron microscope (FESEM) analyses and compared with $B C$ produced with sugar. Furthermore, the viscoelastic properties of BC produced from aqueous extracts of orange peel were also evaluated.

\section{Materials and Methods}

\subsection{Materials}

Black tea bags (Sir Bolton, Italy) sucrose (commercial product), vinegar (commercial product) and Kombucha fermented tea were purchased from the local shops. Sodium hydroxide (NaOH, CAS Number 1310-73-2) was purchased from Sigma-Aldrich and used without further modification. Orange extract was obtained mixing orange peel and pulp (waste from food industry) with water in a weight ratio $1: 2$ and by heating it at $90^{\circ} \mathrm{C}$ for $30 \mathrm{~min}$ or $1 \mathrm{~h}$. After that, the extract was filtered with a paper filter and cooled down to room temperature.

\subsection{Bacterial Cellulose Production}

Bacterial cellulose pellicles were obtained from Kombucha strains by the fermentation process of the sweetened black tea with Gluconacetobacter xilinus strains. The tea fungus, composed of an upper cellulosic pellicle and a lower liquid broth, was activated every 2 weeks according to a procedure inspired to the work of Chen and Liu but with some modifications [26]. The culture medium was prepared by adding sucrose and tea bags to boiling water $(1 \mathrm{~L})$. In case of BC from orange source, named BC_Orange samples, $50 \mathrm{~mL}$ of orange peel extract was added as a sugar source. As a control, BC samples were produced by adding $70 \mathrm{~g}$ of sugar. After removing the tea bags, the $\mathrm{pH}$ value of the broth was adjusted to 3 by adding acetic acid. Finally, the cellulosic pellicle pieces and liquid broth of the tea fungus were added to the cooled tea broth. The fermentation and $\mathrm{BC}$ growth were carried at room temperature $\left(28^{\circ} \mathrm{C}\right)$ for 21 days in a static condition. Cellulose hydrogels spontaneously formed on the surface of the broth. These pellicles and the tea fungus were 
used to inoculate new fermentations. The pellicles were washed with distilled water and soak in $0.5 \mathrm{M} \mathrm{NaOH}$ solution at $80^{\circ} \mathrm{C}$ for 120 min under mild shaking conditions to remove any attached cells and impurities. The BC was rinsed in distilled water to remove $\mathrm{NaOH}$ and, at this stage, BC could be used for further experimentation and for morphological characterization. For microstructural investigations, the pellicles were freeze-dried to retain the 3D weblike structure. Samples were placed in freeze dryer for $24 \mathrm{~h}$ at $-40{ }^{\circ} \mathrm{C}$ and a pressure of 0.01 mbar for drying. A schematic representation of the synthesis procedure from orange peel extract is reported in Figure 1. BC production efficiency was evaluated by measuring the thickness of five samples of BC at different time intervals by means of a caliper. A statistical analysis by means of a Student's $t$-test was carried out to evaluate whether differences in mean values were significant or not. The $t$-test, in fact, evaluated the probability that the difference between the means of the results could have been caused by the chance [27]. The 1st percentile was chosen as the level for statistical significance, i.e., if in the $t$-test showed that the probability, p, was lower than 0.01 , the difference between the two populations was considered to be significant.

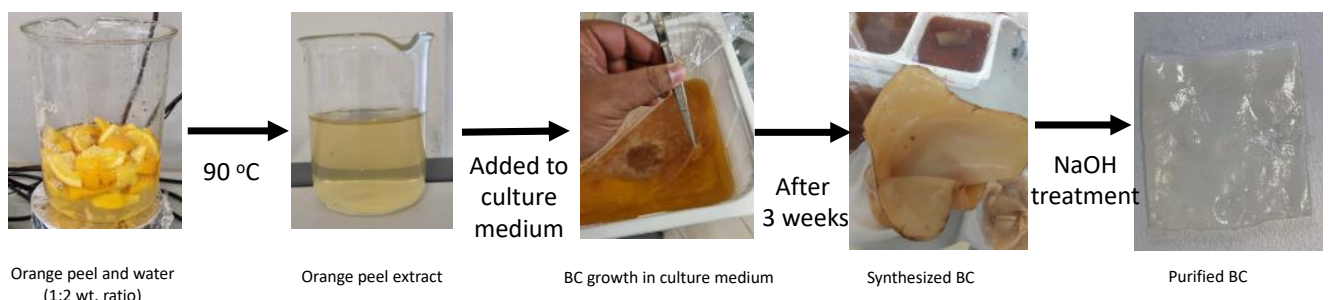

Figure 1. Schematic illustration of BC synthesis from orange peel extract.

\subsection{Porosity and Water Holding Capacity}

The porosities of the freeze-dried hydrogels were calculated according to Equation (1)

$$
\text { Porosity }(\%)=\left(1-\left(\rho / \rho_{0}\right)\right) * 100
$$

where $\rho$ is the apparent density of BC, which was calculated by measuring weight and volume of at least three samples, while $\rho_{0}$ was the theoretical density of bacterial cellulose, equal to $1.59 \mathrm{~g} / \mathrm{cm}^{3}$ [11].

Water holding capacity (WHC) was determined using a gravimetric method. Initially, wet BC samples were weighed $\left(\mathrm{m}_{\mathrm{w}}\right)$. Then, the samples were dried at $50{ }^{\circ} \mathrm{C}$ for $24 \mathrm{~h}$ to obtain the dried weight of BC $\left(\mathrm{m}_{\mathrm{d}}\right)$.

WHC was calculated by the ratio [28]:

$$
\mathrm{WHC}=\mathrm{m}_{\mathrm{w}} / \mathrm{m}_{\mathrm{d}}
$$

The measurement was repeated at least on three replicates for each sample typology.

\subsection{Characterization}

The sucrose, glucose and fructose concentrations in orange extract were quantified onto an Agilent Hi-Plex Ca column $(300 \mathrm{~mm} \times 7.7 \mathrm{~mm})$ with internal particles of $8.0 \mu \mathrm{m}$ (Agilent Technologies, Santa Clara, CA, USA). The mobile phase used was deionized water and a constant flow rate of $0.6 \mathrm{~mL} \mathrm{~min}^{-1}$ for a run time of $30 \mathrm{~min}$. Sugar detection was carried out using a refractive index detector (RID) [29]. The quantification of individual sugars was performed directly by ChemStation software (Agilent, Santa Clara, CA, USA) using a five-point regression curve $\left(\mathrm{r}^{2} \geq 0.99\right)$ on the basis of authentic standards.

The X-ray diffraction (XRD) patterns of BC and BC_Orange samples in the dry state were recorded on a Rigaku Ultima $X$-Ray diffractometer using Ni-filtered $\mathrm{Cu}$ K $\alpha$ radiation $(\lambda=1.5406 \AA)$ at $40 \mathrm{kV}$. The diffractogram was recorded at $2 \theta$ angles between $5^{\circ}$ and $45^{\circ}$. 
The crystallinity index $(\mathrm{CI})$ of the two samples was estimated according to the empirical equation proposed by Segal et al. [30]

$$
C I=100\left[\left(\mathrm{I}_{002}-\mathrm{I}_{\mathrm{am}}\right) / \mathrm{I}_{002}\right]
$$

where $I_{002}$ is the intensity of the principal diffraction peak at $2 \theta=22.6^{\circ}$ and $I_{a m}$ is the intensity of the amorphous counterpart measured at $2 \theta=18^{\circ}$. The estimated values are presented in Table 1. The average crystallite size of the nanocrystalline cellulose was determined according to the Scherrer's formula [9]:

$$
<L_{002}>=\mathrm{k} \lambda / \beta \operatorname{Cos} \theta
$$

where $L_{002}$ is the average crystallite size, $\mathrm{k}$ is the shape factor (0.9), $\lambda$ is the $\mathrm{X}$-ray wavelength and $\theta$ is the BragG's angle corresponding to the intense (002) diffraction peak.

Table 1. Content of sugar and reducing sugars in orange peel extract.

\begin{tabular}{ccccc}
\hline Sample & Sucrose & Glucose & Fructose & Total Sugar \\
\hline \multicolumn{4}{c}{$\mathrm{g} / \mathrm{L}$} \\
\hline Orange extract & $24.77 \pm 0.99$ & $25.46 \pm 1.02$ & $25.49 \pm 0.76$ & $75.72 \pm 3$ \\
\hline
\end{tabular}

Fourier transform infrared spectra (FTIR) were recorded for dried cellulose samples in attenuated total reflectance (ATR) mode with a Perkin Elmer Spectrum One spectrometer at wavelength range of $4000-400 \mathrm{~cm}^{-1}$ with a resolution of $4 \mathrm{~cm}^{-1}$. Morphological characterizations of the samples were performed on a Zeiss (Sigma VP, Carl Zeiss, Jena, Germany) field-emission scanning electron microscope (FESEM). To perform the analyses on microstructure, a thin slice was cut from the freeze-dried cellulose with a sharp stainless-steel blade and placed on the carbon tape of the sample holder.

The viscoelastic properties of bacterial cellulose were investigated by dynamic mechanical analysis using parallel plates geometry ARES rheometer from TA instruments (New Castle, DE, USA). Samples of wet bacterial cellulose in the form of discs of $25 \mathrm{~mm}$ diameter and $1 \mathrm{~mm}$ thickness were tested at $20{ }^{\circ} \mathrm{C}$. In order to determine the linear viscoelastic regime, dynamic strain sweep measurements at a frequency of $1 \mathrm{~Hz}$ with strain ranging between $0.01 \%$ and $100 \%$ were performed. Then, frequency sweeps between 0.01 and $100 \mathrm{~Hz}$ were applied over a linear strain $(0.02 \%)$ at $20{ }^{\circ} \mathrm{C}$.

\section{Results and Discussion}

\subsection{Bacterial Cellulose Production}

$\mathrm{BC}$ production was monitored by measuring the thickness of the $\mathrm{BC}$ hydrogel every 7 days as reported in Figure 2. It is evident that BC_Orange forms thicker cellulose than BC at each time interval. After a 21-day culture, cellulose gel that is almost $40 \%$ thicker was formed for $\mathrm{BC} \_$Orange. The results were statistically analyzed by $t$-test and the difference between BC and BC_Orange thickness at each time interval (7, 14 and 21 days) was found to be statistically significant at this point. The $1 \%$ percentile was chosen as the level for statistical significance, i.e., if in the $t$-test the probability $p$ is lower than 0.01 , the difference between the two populations was considered to be significant [31]. This indicates that the orange peel extract is an efficient medium for a fast growth of BC. 


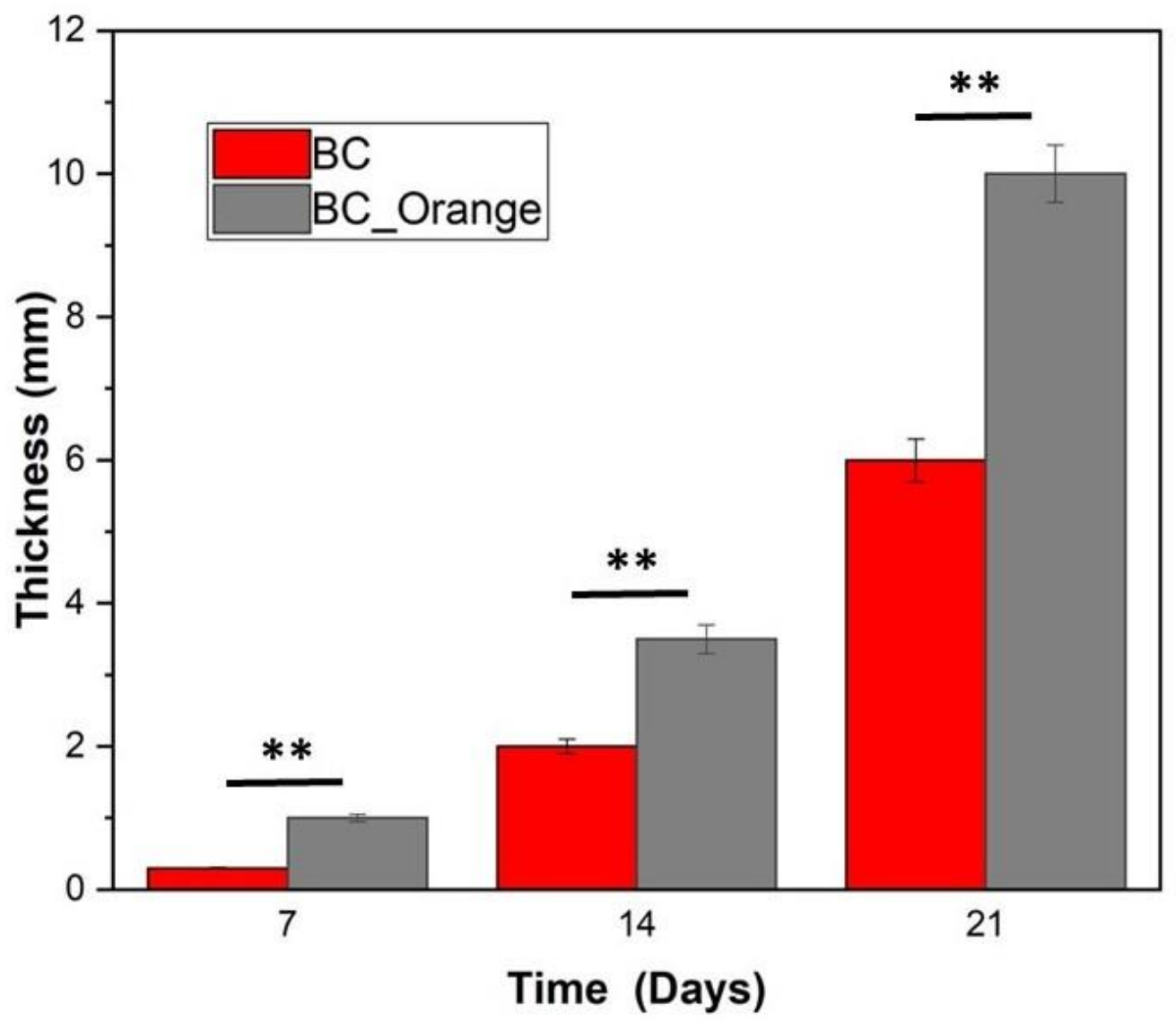

Figure 2. Thickness of BC produced at different time periods (values are reported as the average of 5 replicates). The asterisks ${ }^{* *}$ represent the significance level at $99 \%$ confidence interval.

Table 1 shows the concentration of sugar and reducing sugars in orange peel extract. According to the literature, reducing sugars are the main nutrient sources in all $\mathrm{BC}$ cultivations [32]. The orange peel extract used in this work has a total sugar content of $75.72 \mathrm{~g} / \mathrm{L}$, which is nearly equally divided among sucrose $(24.77 \mathrm{~g} / \mathrm{L})$, glucose $(25.46 \mathrm{~g} / \mathrm{L})$ and fructose $(25.49 \mathrm{~g} / \mathrm{L})$. The total sugar content is higher than that of the HS medium, which contains glucose (25.5 g/L) as well as other components in less quantity [17]. Moreover, the presence of high glucose and fructose content might explain the increased yield of $\mathrm{BC}$ film from the orange peel extract than $\mathrm{BC}$ obtained from sucrose. It indicates that orange peel extract can be considered as a potentially low-cost and high-yield medium for obtaining bacterial cellulose.

BC_Orange shows a high porosity value of $98 \%$, whereas $\mathrm{BC}$ has a slightly less porous nature (porosity 92\%). For biomedical and food industry applications, the water holding capacity (WHC) of BC has an important role [33]. The WHC capacity of BC has been attributed in the literature to the formation of intra- and intermolecular hydrogen bonds by numerous hydroxyl groups present in the cellulose fibrils [34]. In this work, the WHC of the produced BC_Orange is equal to $101 \pm 5$, whereas BC shows less than half, i.e., $45 \pm 3$. This indicates that BC_Orange has twice the capacity to hold water than BC. This result is a further indication of the efficacy of orange extract as an efficient medium for the synthesis of BC.

\subsection{XRD Results}

The crystallinity of $\mathrm{BC}$ and BC_Orange samples was evaluated from XRD analysis and reported in Table 2. Figure 3 shows the XRD pattern recorded on both samples. For BC, the appearance of strong diffraction peaks at $2 \theta 14.4^{\circ}, 16.6^{\circ}, 22.6^{\circ}, 27.8^{\circ}$ and $29.3^{\circ}$ can be attributed to the Miller indices of the diffraction planes of (101), (111), (002), (130) and (122), 
respectively, of the crystalline cellulose (JCPDS \#03-0829) [35]. This set of diffraction planes corresponds to the highly crystalline native cellulose I composed of $\mathrm{I}_{\alpha}$ and $\mathrm{I}_{\beta}$ allomorphs. On the other hand, the spectrum of BC_Orange presents peaks at $2 \theta 14.4^{\circ}, 16.6^{\circ}$ and $22.6^{\circ}$, attributed to the Miller indices of the diffraction planes of (101), (111) and (002). This indicates that the BC produced from orange peel only in part retains the crystallinity of bacterial cellulose.

Table 2. Physical parameters determined from XRD analysis.

\begin{tabular}{cccccc}
\hline Samples & $\boldsymbol{C I}(\mathbf{\%})^{\mathbf{a}}$ & $\mathbf{2 \theta}$ & FWHM $^{\mathbf{b}}$ & $\left\langle D_{a v}\right\rangle(\mathbf{n m})^{\mathbf{c}}$ & $d_{\text {-Spacing }(\mathbf{n m})^{\mathbf{d}}}$ \\
\hline BC & $72.52 \pm 1.2$ & 22.65 & $1.83 \pm 0.01$ & $4.63 \pm 0.05_{(002)}$ & 0.392 \\
BC_Orange & $85.31 \pm 1.5^{* *}$ & 22.81 & $1.417 \pm 0.01$ & $5.97 \pm 0.07_{(002)}$ & 0.389 \\
\hline
\end{tabular}

a Crystallinity index. ${ }^{\mathrm{b}}$ Full width half maxima from the XRD peak. ${ }^{\mathrm{c}}$ Average crystallite size using Scherrer equation. $h k l$ parameters of respective $2 \theta$ values used in Scherrer equation are listed as subscript. ${ }^{\mathrm{d}}$ calculated by the BragG's law: $\lambda=2 d \sin (\theta) .{ }^{* *}$ Statistically significant difference from the BC samples at the $99 \%$ confidence level.

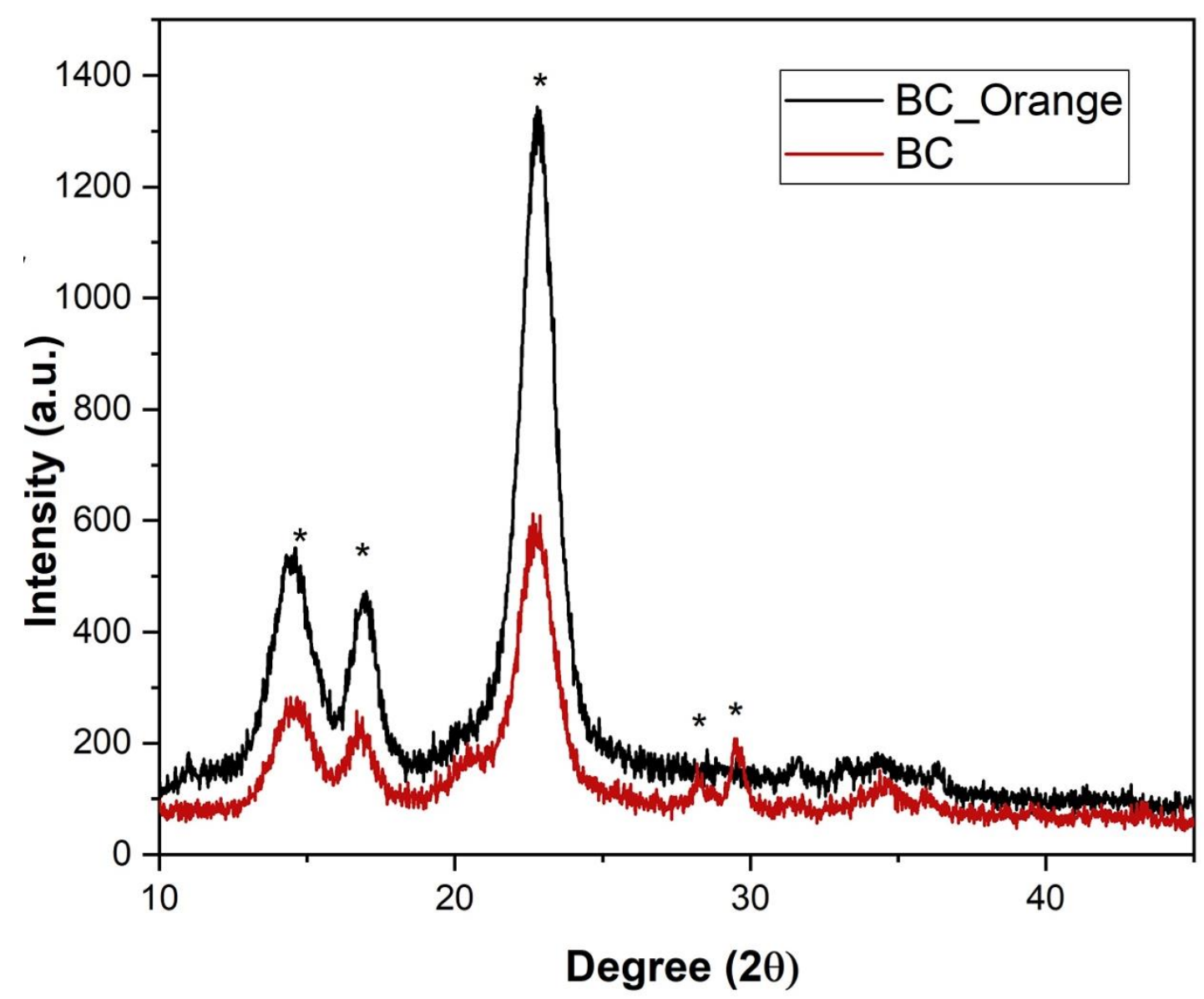

Figure 3. XRD patterns of bacterial cellulose produced from orange peel extract (BC_Orange) and sucrose $(\mathrm{BC}) .{ }^{*}$ denotes the indexed crystalline peaks.

BC_Orange shows higher crystallinity (CI 85\%) compared to BC (72\%). The BC control samples have $\mathrm{CI}$ comparable with literature data for BC biosynthesized by Gluconacetobacter xylinus, ranging from $65 \%$ to $75 \%$ [36]. There were many factors such as cultivation method, carbon sources, $\mathrm{pH}$, temperature, fermentation time and drying methods affecting the crystallinity of BC. In our study, the reduced carbon source from orange peel extract might strongly influence the enhanced properties of $\mathrm{BC}$ by providing the nutrients (glucose and fructose) required for bacterial growth $[37,38]$. 


\subsection{FTIR Results}

The functional groups and chemical bonds present in BC and BC_Orange cellulose fibers can be inferred from the FTIR spectra presented in Figure 4. The absorption region at 800 and $1200 \mathrm{~cm}^{-1}$ was considered to be the fingerprint region for carbohydrates, allowing the identification of important chemical groups in polysaccharides [1]. The broad vibration band at the $3200-3400 \mathrm{~cm}^{-1}$ region was assigned to the $\mathrm{OH}$ stretching vibration of the hydroxyl groups present in the bacterial cellulose network. Two relatively smaller bands at $2800-2900 \mathrm{~cm}^{-1}$ and a strong band at $1425 \mathrm{~cm}^{-1}$ were assigned to the stretching vibrations of $\mathrm{CH}$ and $\mathrm{CH}_{2}$, respectively. The absorption at $1158 \mathrm{~cm}^{-1}$ was derived from the $\mathrm{C}-\mathrm{O}-\mathrm{C}$ stretching vibration of the cellulose matrix. A group of absorption peaks at the wavenumber region of $1200-900 \mathrm{~cm}^{-1}$ arose from the $\mathrm{C}-\mathrm{O}$ and $\mathrm{C}-\mathrm{C}$ stretching vibrations of the cellulose network [39]. Relatively weaker peaks at lower wavenumbers were characteristic of the fibril cellulose network. BC and BC_Orange samples present similar FTIR spectra without noticeable changes in the frequencies. This indicates that there are no significant differences in the chemical composition of the two different kinds of bacterial cellulose, despite the carbon source being different. The vibrational spectra show similar bands at different frequencies. The difference in the intensities of various bands could be due to the different thickness of the cellulose samples used in FTIR measurements.

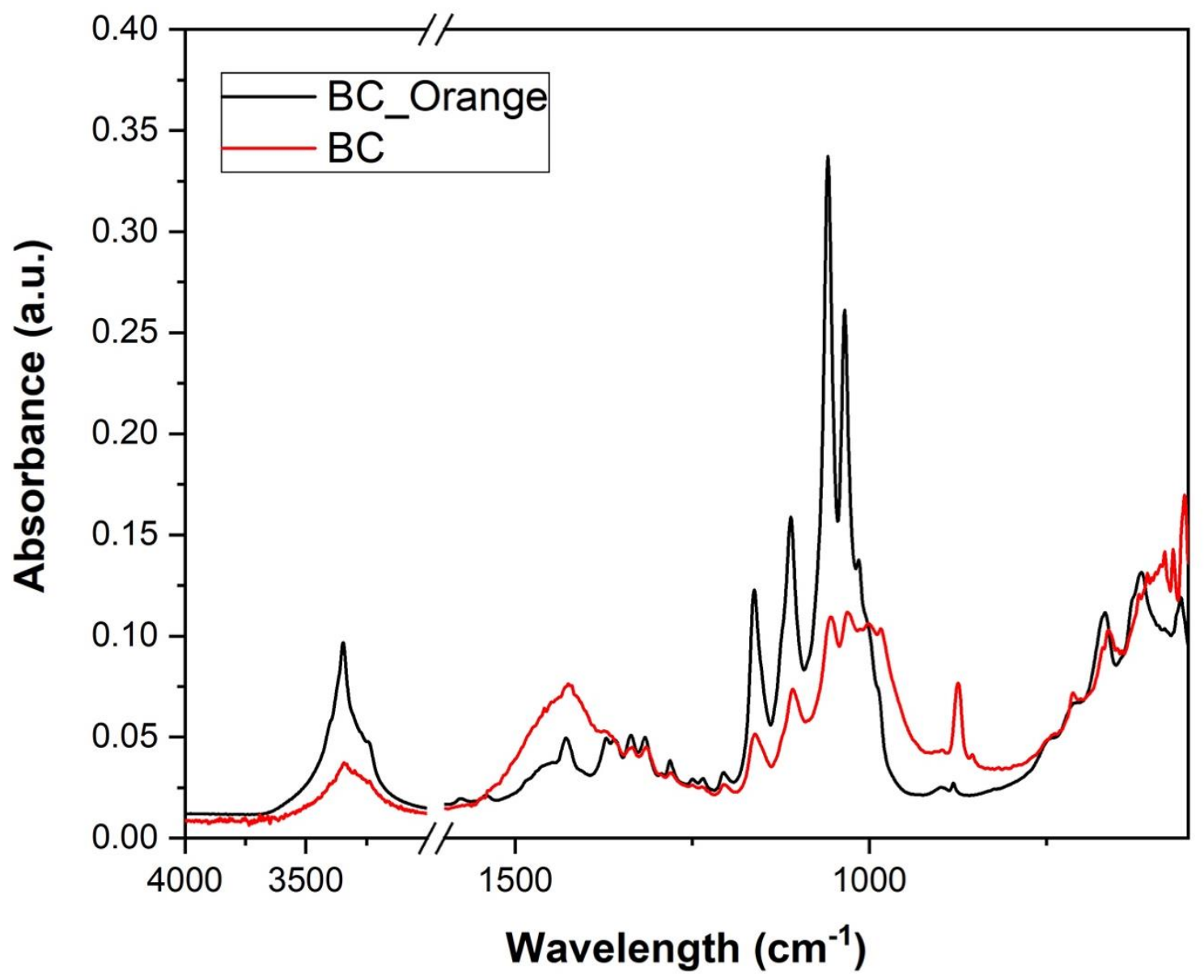

Figure 4. FTIR spectra of bacterial cellulose produced from orange peel extract (BC_Orange) and from sucrose (BC).

\subsection{Morphology by SEM Analyis}

The morphological analysis is presented in Figure 5, which shows the FESEM images from the BC (Figure 5a,b) and BC_Orange (Figure 5c,d). From Figure 5a-c, it is clear that both BC and BC_Orange are composed of a 3D web-like porous structure with cellulose nanofibers. The nanometer-sized fibers are distributed and interconnected in such a way 
to form a finely woven porous structure. Image analysis was carried out using Image J software in order to measure fiber diameters. As reported in the inset of Figure $5 b, d$, there was no substantial difference in the fiber diameter; the average values were $50 \pm 20 \mathrm{~nm}$ and $53 \pm 23 \mathrm{~nm}$ for BC_Orange and BC, respectively. These values were the average of at least 100 measurements for each BC typology.
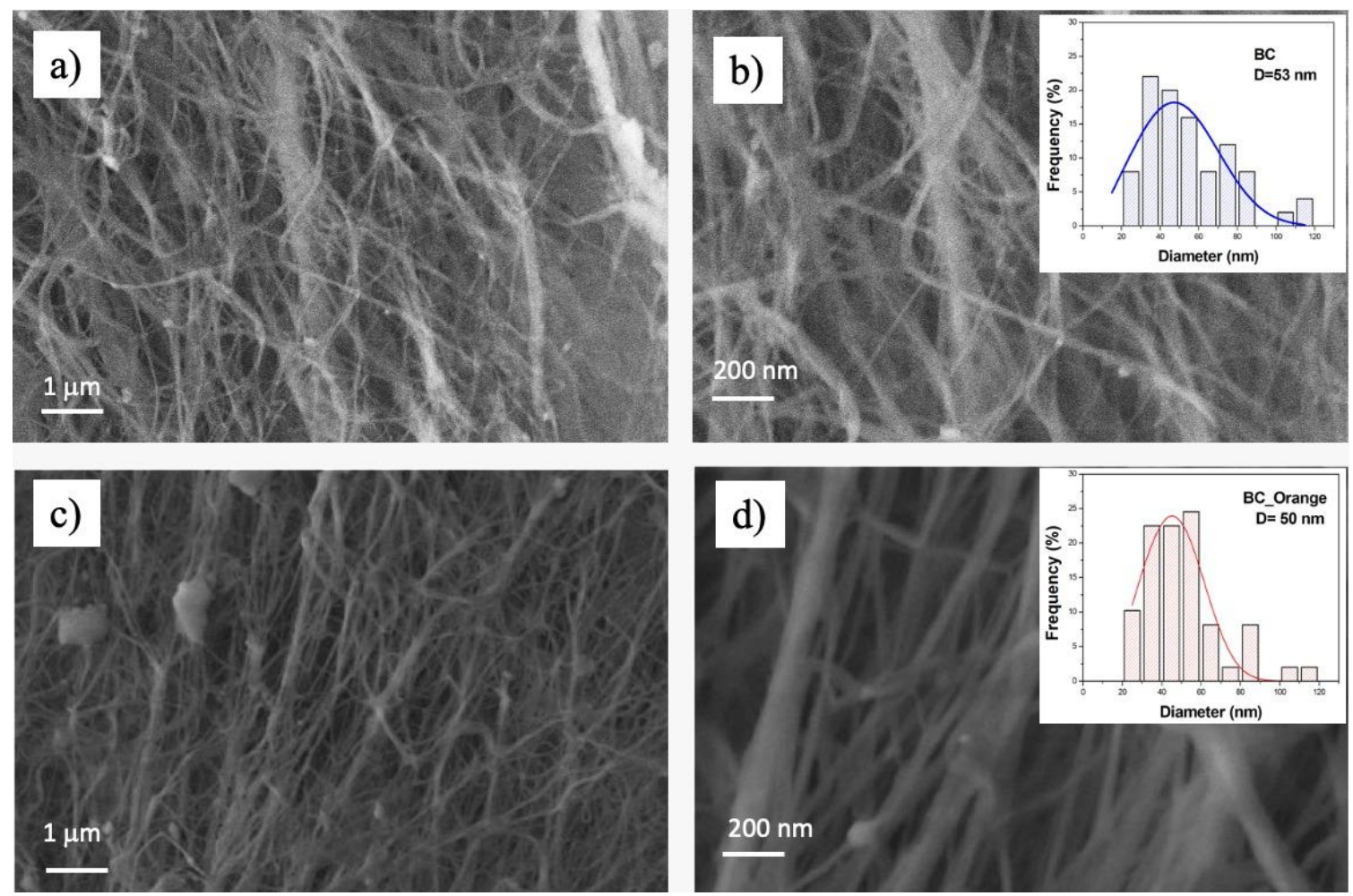

Figure 5. Scanning electron microscopy of bacterial cellulose produced from sucrose $(\mathbf{a}, \mathbf{b})$ and from orange peel extract $(\mathbf{c}, \mathbf{d})$ at different magnifications. The inset shows the fiber diameter distribution in each sample.

\subsection{Dynamic Mechanical Analysis}

Dynamic mechanical analysis was used to investigate the viscoelastic properties of BC_Orange and BC samples. The effect of shear strain in the storage $\left(\mathrm{G}^{\prime}\right)$ and loss $\left(\mathrm{G}^{\prime \prime}\right)$ modulus in a dynamic strain sweep measurement is reported in Figure 6. At very low strain values, the storage modulus $\left(G^{\prime}\right)$ is about 5-6 times higher than the loss modulus $\left(G^{\prime \prime}\right)$. This indicates that both BC and BC-Orange samples show gel- or solid-like behavior in the linear viscoelastic region, resulting from the formation of a three-dimensional network. During the strain sweep measurements, the storage modulus $\mathrm{G}^{\prime}$ remains constant until the oscillation stress overcomes the intermolecular forces. The maximum strain $\left(\gamma_{\text {crit }}\right)$, to which the linear viscoelastic region extends, was determined as the value above which $\mathrm{G}^{\prime}$ decreases more than $10 \%$ of the maximum value [40]. It is equal to $0.186 \%$ and $0.084 \%$ for $\mathrm{BC}$-Orange an $\mathrm{BC}$, respectively. This means that the procedure using the orange waste can increase the maximum shear strain that can be applied to the system whilst maintaining the condition of linear viscoelasticity. 


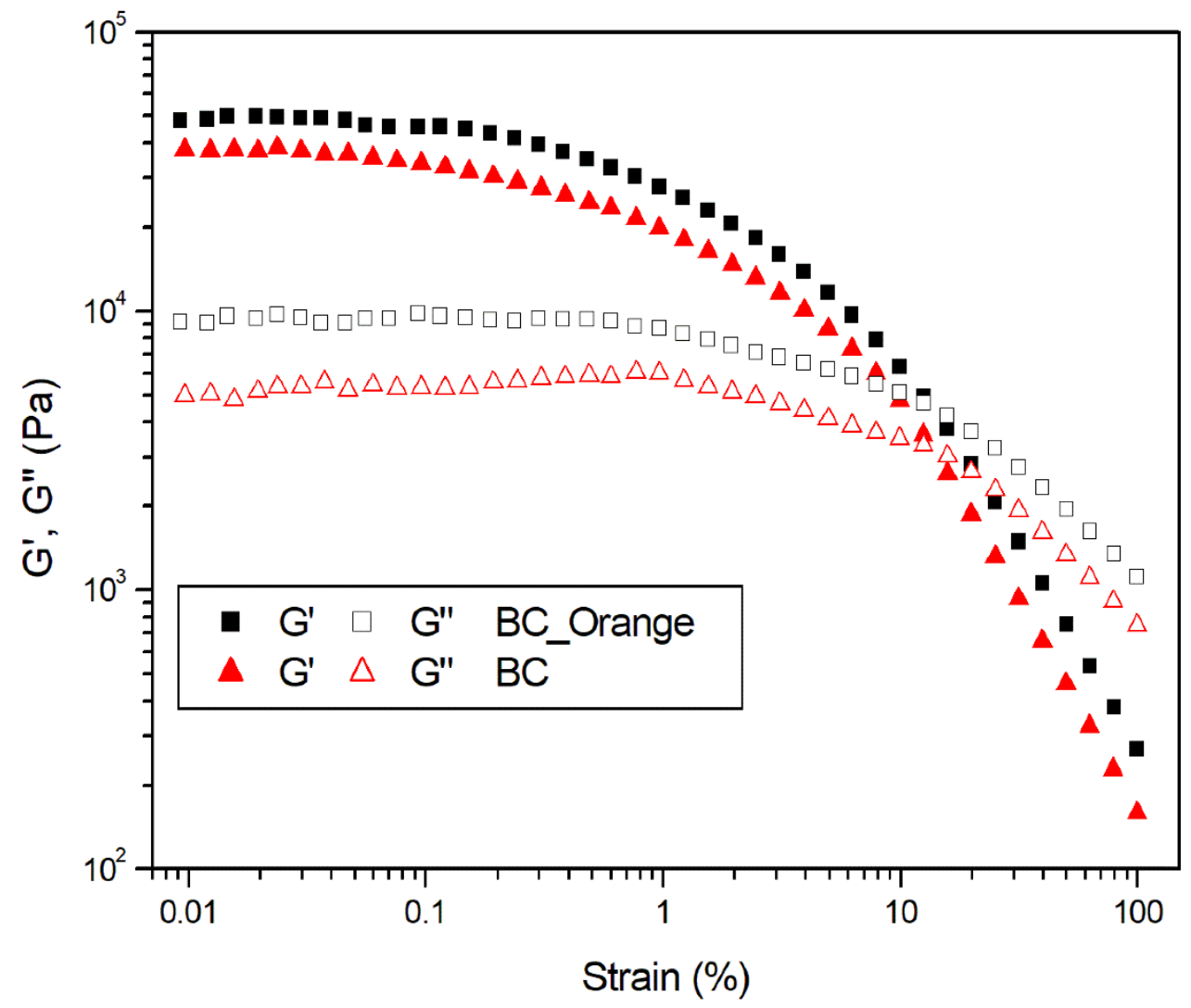

Figure 6. Dynamic strain sweep at $1 \mathrm{~Hz}$ on bacterial cellulose hydrogels produced from orange peel extract (BC_Orange) and sucrose (BC).

A frequency sweep test was carried out at shear strains within the linear viscoelastic region, where the material response is independent of the magnitude of the deformation and the material structure remains intact. The DMA curves reported in Figure 7 show that, for each sample, $G^{\prime}$ is higher than $G^{\prime \prime}$ in the whole experimental frequency range. Therefore, all the samples behave as self-standing hydrogels, with the elastic behavior dominant compared to the viscous one. At $1 \mathrm{~Hz}$, an increase in the $\mathrm{G}^{\prime}$ of $44 \%$ from $32.84 \mathrm{kPa}$ to $47.18 \mathrm{kPa}$ for BC and BC_Orange, respectively, was observed. This can be ascribed to both a higher number of fiber entanglements in the bacterial cellulose hydrogel, as reported by Li et al. [41], and to the higher crystallinity content and thickness of the cellulose fibers of BC_Orange samples, as demonstrated by the XRD and SEM results. The higher number of fiber entanglements might be attributed to the citric acid content in the BC_Orange medium, which may act as a carbohydrate cross-linker on BC to cross-link nanofibers thus reinforcing and stiffening the BC network [42]. Therefore, the citric acid content in the medium might positively influence the BC hydrogels, which grow as the higher water holding capability increases. 


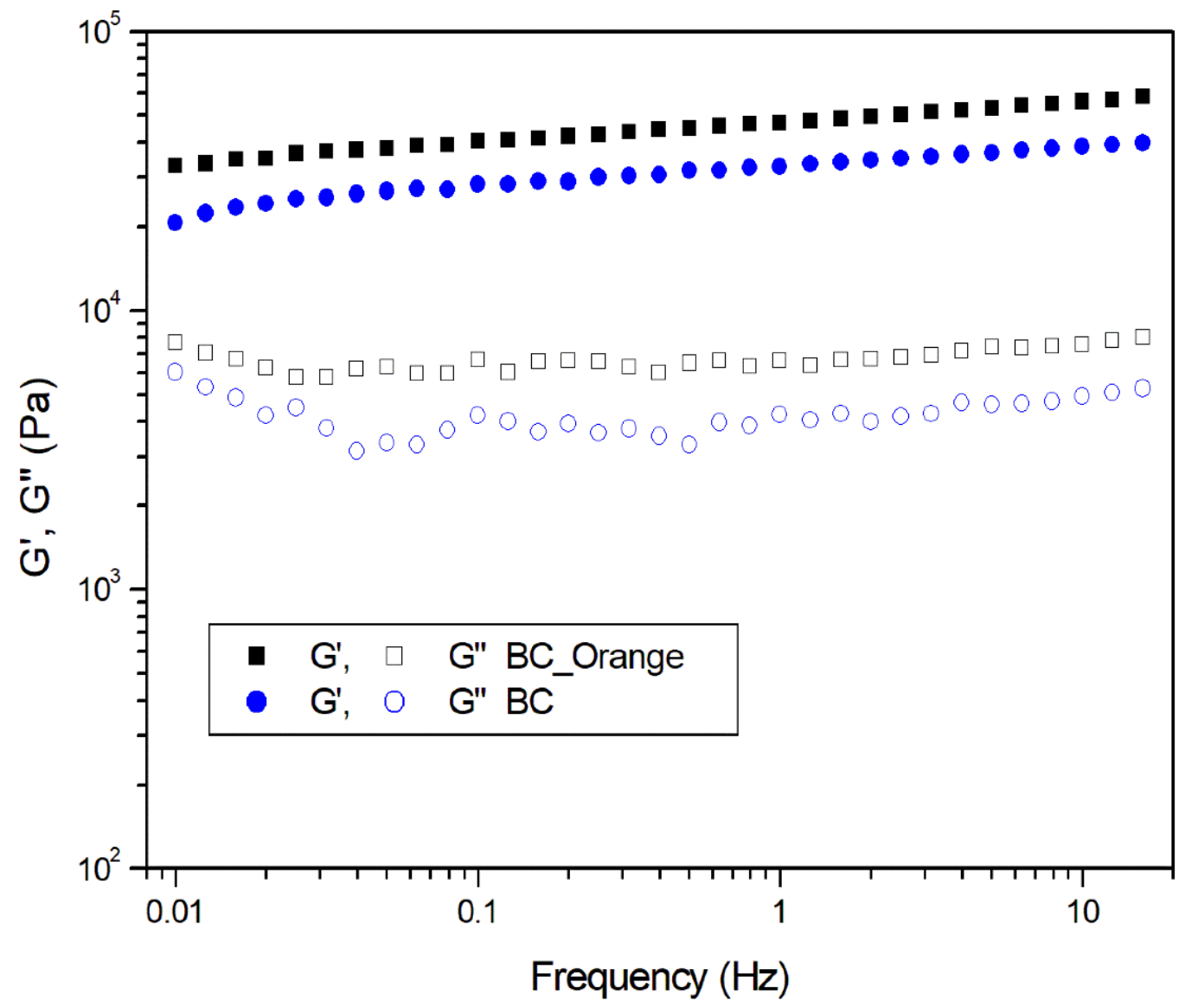

Figure 7. Dynamic frequency sweep test on bacterial cellulose hydrogels produced from orange peel extract (BC_Orange) and sucrose (BC).

\section{Conclusions}

This study demonstrated that orange peel extract without any chemical or enzymatic hydrolysis can be used as an environmentally friendly and cheap medium to produce bacterial cellulose. BC produced from orange peel extract showed different and somewhat superior properties to the cellulose obtained from the sucrose feed which was used as a reference. It has been suggested that citric acid may act as a carbohydrate cross-linker on $\mathrm{BC}$ to cross-link nanofibers and maintain the 3D structure of $\mathrm{BC}$ pellicles. Therefore, the citric acid content in the medium might positively influence the $\mathrm{BC}$ hydrogels, which grows with the higher water holding capability. The use of orange peel extract as a substitute carbon source resulted in a higher yield of bacterial cellulose with higher crystallinity, water holding capacity and elastic properties than the BC produced as a reference. FTIR showed there were no significant chemical differences between the two kinds of $\mathrm{BC}$ obtained.

Author Contributions: Conceptualization, S.K.P., F.L., R.N., M.S. and A.L.; methodology, S.K.P., F.L. and R.N.; software, S.K.P. and F.L.; validation, S.K.P. and F.L.; formal analysis, S.K.P. and F.L.; investigation, S.K.P., F.L., R.N., M.S. and A.L.; resources, M.S. and A.L.; data curation, S.K.P. and F.L.; writing —original draft preparation, S.K.P. and F.L.; writing—review and editing, S.K.P., F.L., R.N., M.S. and A.L.; visualization, S.K.P., F.L. and A.L.; supervision, A.L.; project administration, S.K.P.; funding acquisition, A.L. All authors have read and agreed to the published version of the manuscript.

Funding: S.K.P acknowledges Regione Puglia for funding REFIN-Research for Innovation project "Medicazioni innovative per rigenerazione tissutale a base di idrogeli funzionalizzati di cellulosa batterica", project no. 8AE55352, in the framework of POR PUGLIA FESR-FSE 2014/2020 projects.

Institutional Review Board Statement: Not applicable. 
Informed Consent Statement: Not applicable.

Data Availability Statement: Not applicable.

Acknowledgments: Donato Cannoletta of the University of Salento is kindly acknowledged for the support in SEM and XRD measurements. Leone D'Amico of the Institute of Sciences of Food Production, National Research Council (Lecce) is kindly acknowledged for the measurement of sugar content.

Conflicts of Interest: The authors declare no conflict of interest.

\section{References}

1. Klemm, D.; Schumann, D.; Udhardt, U.; Marsch, S. Bacterial synthesized cellulose-Artificial blood vessels for microsurgery. Prog. Polym. Sci. 2001, 26, 1561-1603. [CrossRef]

2. Ilyas, R.A.; Sapuan, S.M.; Ishak, M.R.; Zainudin, E.S. Development and characterization of sugar palm nanocrystalline cellulose reinforced sugar palm starch bionanocomposites. Carbohydr. Polym. 2018, 202, 186-202. [CrossRef] [PubMed]

3. Ilyas, R.A.; Sapuan, S.M.; Ishak, M.R.; Zainudin, E.S. Sugar palm nanofibrillated cellulose (Arenga pinnata (Wurmb.) Merr): Effect of cycles on their yield, physic-chemical, morphological and thermal behavior. Int. J. Biol. Macromol. 2019, 123, 379-388. [CrossRef] [PubMed]

4. Jung, H.-I.; Jeong, J.-H.; Lee, O.-M.; Park, G.-T.; Kim, K.-K.; Park, H.-C.; Lee, S.-M.; Kim, Y.-G.; Son, H.-J. Influence of glycerol on production and structural-physical properties of cellulose from Acetobacter sp. V6 cultured in shake flasks. Bioresour. Technol. 2010, 101, 3602-3608. [CrossRef] [PubMed]

5. Singh, O.; Panesar, P.S.; Chopra, H.K. Response surface optimization for cellulose production from agro industrial waste by using new bacterial isolate Gluconacetobacter xylinus C18. Food Sci. Biotechnol. 2017, 26, 1019-1028. [CrossRef] [PubMed]

6. Chen, Y.W.; Lee, H.V.; Juan, J.C.; Phang, S.-M. Production of new cellulose nanomaterial from red algae marine biomass Gelidium elegans. Carbohydr. Polym. 2016, 151, 1210-1219. [CrossRef] [PubMed]

7. Sohail, M.; Ahmad, A.; Khan, S.A. Production of cellulase from Aspergillus terreus MS105 on crude and commercially purified substrates. 3 Biotech. 2016, 6, 103. [CrossRef]

8. Klemm, D.; Heublein, B.; Fink, H.-P.; Bohn, A. Cellulose: Fascinating Biopolymer and Sustainable Raw Material. Angew. Chem. Int. Ed. 2005, 44, 3358-3393. [CrossRef]

9. Pal, S.; Nisi, R.; Stoppa, M.; Licciulli, A. Silver-Functionalized Bacterial Cellulose as Antibacterial Membrane for Wound-Healing Applications. ACS Omega 2017, 2, 3632-3639. [CrossRef]

10. Santos, S.M.; Carbajo, J.M.; Quintana, E.; Ibarra, D.; Gomez, N.; Ladero, M.; Eugenio, M.E.; Villar, J.C. Characterization of purified bacterial cellulose focused on its use on paper restoration. Carbohydr. Polym. 2015, 116, 173-181. [CrossRef]

11. Padmanabhan, S.K.; Protopapa, C.; Licciulli, A. Stiff and tough hydrophobic cellulose-silica aerogels from bacterial cellulose and fumed silica. Process Biochem. 2021, 103, 31-38. [CrossRef]

12. Padmanabhan, S.K.; Corcione, C.E.; Nisi, R.; Maffezzoli, A.; Licciulli, A. PolyDiethyleneglycol-bisallyl carbonate matrix transparent nanocomposites reinforced with bacterial cellulose microfibrils. Eur. Polym. J. 2017, 93, 192-199. [CrossRef]

13. Shi, Z.; Zhang, Y.; Phillips, G.O.; Yang, G. Utilization of bacterial cellulose in food. Food Hydrocoll. 2014, 35, 539-545. [CrossRef]

14. Sureshkumar, M.; Siswanto, D.Y.; Lee, C.-K. Magnetic antimicrobial nanocomposite based on bacterial cellulose and silver nanoparticles. J. Mater. Chem. 2010, 20, 6948-6955. [CrossRef]

15. Zhong, C. Industrial-Scale Production and Applications of Bacterial Cellulose. Front. Bioeng. Biotechnol. 2020, 8, 1425. [CrossRef] [PubMed]

16. Azimi, B.; Milazzo, M.; Danti, S. Cellulose-Based Fibrous Materials From Bacteria to Repair Tympanic Membrane Perforations. Front. Bioeng. Biotechnol. 2021, 9, 474. Available online: https://www.frontiersin.org/article/10.3389/fbioe.2021.669863 (accessed on 24 January 2022). [CrossRef] [PubMed]

17. Hestrin, S.; Schramm, M. Synthesis of cellulose by Acetobacter xylinum. 2. Preparation of freeze-dried cells capable of polymerizing glucose to cellulose. Biochem. J. 1954, 58, 345-352. [CrossRef]

18. Hong, F.; Qiu, K. An alternative carbon source from konjac powder for enhancing production of bacterial cellulose in static cultures by a model strain Acetobacter aceti subsp. xylinus ATCC 23770. Carbohydr. Polym. 2008, 72, 545-549. [CrossRef]

19. Khami, S.; Khamwichit, W.; Suwannahong, K.; Sanongraj, W. Characteristics of Bacterial Cellulose Production from Agricultural Wastes. Adv. Mater. Res. 2014, 931, 693-697. [CrossRef]

20. de Medina-Salas, L.; Giraldi-Díaz, M.R.; Castillo-González, E.; Morales-Mendoza, L.E. Valorization of Orange Peel Waste Using Precomposting and Vermicomposting Processes. Sustainability 2020, 12, 7626. [CrossRef]

21. Kurosumi, A.; Sasaki, C.; Yamashita, Y.; Nakamura, Y. Utilization of various fruit juices as carbon source for production of bacterial cellulose by Acetobacter xylinum NBRC 13693. Carbohydr. Polym. 2009, 76, 333-335. [CrossRef]

22. Andritsou, V.; de Melo, E.M.; Tsouko, E.; Ladakis, D.; Maragkoudaki, S.; Koutinas, A.A.; Matharu, A.S. Synthesis and Characterization of Bacterial Cellulose from Citrus-Based Sustainable Resources. ACS Omega 2018, 3, 10365-10373. [CrossRef] [PubMed] 
23. Pocan, P.; Bahcegul, E.; Oztop, M.H.; Hamamci, H. Enzymatic Hydrolysis of Fruit Peels and Other Lignocellulosic Biomass as a Source of Sugar. Waste Biomass Valor. 2018, 9, 929-937. [CrossRef]

24. Grohmann, K.; Cameron, R.G.; Buslig, B.S. Fractionation and pretreatment of orange peel by dilute acid hydrolysis. Bioresour. Technol. 1995, 54, 129-141. [CrossRef]

25. Kuo, C.-H.; Huang, C.-Y.; Shieh, C.-J.; Wang, H.-M.D.; Tseng, C.-Y. Hydrolysis of Orange Peel with Cellulase and Pectinase to Produce Bacterial Cellulose using Gluconacetobacter xylinus. Waste Biomass Valor. 2019, 10, 85-93. [CrossRef]

26. Chen, C.; Liu, B.Y. Changes in major components of tea fungus metabolites during prolonged fermentation. J. Appl. Microbiol. 2000, 89, 834-839. [CrossRef]

27. Lionetto, F.; Frigione, M. Mechanical and natural durability properties of wood treated with a novel organic preservative/consolidant product. Mater. Des. 2009, 30, 3303-3307. [CrossRef]

28. Ogrizek, L.; Lamovšek, J.; Čuš, F.; Leskovšek, M.; Gorjanc, M. Properties of Bacterial Cellulose Produced Using White and Red Grape Bagasse as a Nutrient Source. Processes 2021, 9, 1088. [CrossRef]

29. Lam, M.K.; Tan, I.S.; Lee, K.T. Utilizing lipid-extracted microalgae biomass residues for maltodextrin production. Chem. Eng. J. 2014, 235, 224-230. [CrossRef]

30. Segal, R.L.; Creely, J.J.; Martin, A.E.; Conrad, C.M. An Empirical Method for Estimating the Degree of Crystallinity of Native Cellulose Using the X-Ray Diffractometer. Text. Res. J. 1959, 29, 786-794. [CrossRef]

31. Lionetto, F.; Frigione, M. Effect of novel consolidants on mechanical and absorption properties of deteriorated wood by insect attack. J. Cult. Herit. 2012, 13, 195-203. [CrossRef]

32. Kiziltas, E.E.; Kiziltas, A.; Gardner, D.J. Synthesis of bacterial cellulose using hot water extracted wood sugars. Carbohydr. Polym. 2015, 124, 131-138. [CrossRef] [PubMed]

33. Lin, S.-P.; Calvar, I.L.; Catchmark, J.M.; Liu, J.-R.; Demirci, A.; Cheng, K.-C. Biosynthesis, production and applications of bacterial cellulose. Cellulose 2013, 20, 2191-2219. [CrossRef]

34. Rebelo, A.R.; Archer, A.J.; Chen, X.; Liu, C.; Yang, G.; Liu, Y. Dehydration of bacterial cellulose and the water content effects on its viscoelastic and electrochemical properties. Sci. Technol. Adv. Mater. 2017, 18, 203-211. [CrossRef] [PubMed]

35. Zhu, C.; Li, F.; Zhou, X.; Lin, L.; Zhang, T. Kombucha-synthesized bacterial cellulose: Preparation, characterization, and biocompatibility evaluation. J. Biomed. Mater. Res. A 2014, 102, 1548-1557. [CrossRef] [PubMed]

36. Ruan, C.; Zhu, Y.; Zhou, X.; Abidi, N.; Hu, Y.; Catchmark, J.M. Effect of cellulose crystallinity on bacterial cellulose assembly. Cellulose 2016, 23, 3417-3427. [CrossRef]

37. Güzel, M.; Akpınar, Ö. Production and Characterization of Bacterial Cellulose from Citrus Peels. Waste Biomass Valor. 2019, 10, 2165-2175. [CrossRef]

38. Gomes, F.P.; Silva, N.H.C.S.; Trovatti, E.; Serafim, L.S.; Duarte, M.F.; Silvestre, A.J.D.; Neto, C.P.; Freire, C.S.R. Production of bacterial cellulose by Gluconacetobacter sacchari using dry olive mill residue. Biomass Bioenergy 2013, 55, 205-211. [CrossRef]

39. Czaja, W.; Romanovicz, D.; Brown, R.M. Structural investigations of microbial cellulose produced in stationary and agitated culture. Cellulose 2004, 11, 403-411. [CrossRef]

40. Lionetto, F.; López-Muñoz, R.; Espinoza-González, C.; Mis-Fernández, R.; Rodríguez-Fernández, O.; Maffezzoli, A. A Study on Exfoliation of Expanded Graphite Stacks in Candelilla Wax. Materials 2019, 12, 2530. [CrossRef]

41. Li, Z.; Chen, S.-Q.; Cao, X.; Li, L.; Zhu, J.; Yu, H. Effect of pH Buffer and Carbon Metabolism on the Yield and Mechanical Properties of Bacterial Cellulose Produced by Komagataeibacter hansenii ATCC 53582. J. Microbiol. Microtechnol. 2021, 31, 429-438. [CrossRef] [PubMed]

42. Meftahi, A.; Khajavi, R.; Rashidi, A.; Rahimi, M.K.; Bahador, A. Preventing the collapse of 3D bacterial cellulose network via citric acid. J. Nanostruct. Chem. 2018, 8, 311-320. [CrossRef] 